\title{
Structural changes in small power boilers over the last years
}

\author{
Jarosław Bartoszewicz ${ }^{1, *}$ \\ ${ }^{1}$ Poznan University of Technology, Faculty of Machines and Transport, Chair of Thermal \\ Engineering, Pl. M. Skłodowska-Curie 5, 60-965 Poznań, Poland
}

\begin{abstract}
The aim of this research is to assess the construction of lowtemperature solid fuel boilers with special consideration of changes in their construction over the last years. The results contained in this paper are based on analysis of production program of 130 coal boilers manufacturers from Poland. Attributes which are the main subject of comparison and their classify with reference to compatibility with standards requirements consists with parameters indicating energetic properties of construction such as fuel consumption, heating surface, thermal load of heating surface, boiler efficiency, boiler mass, water capacity, slow-burning, and others. Results are compiled in tables and figures which allows comparing to compare construction features boilers in the same standard class. The main reason for this analysis is to show the direction of boiler industry evolution. These results can be used as construction data for new boilers, or to evaluate already existing boiler.
\end{abstract}

\section{Introduction}

The cities in Poland are among the dustiest cities in Europe. This is a result of the use of solid fuel fired boilers with low efficiency, and fuels with a high content of noncombustible mineral fractures responsible for the emission of dust. The most commonly used direct heat source is water boilers. A water boiler is a device designed to heat water with heat obtained in the process of fuel combustion. Heating boilers [6] have specific construction features, heating medium parameters, and thermal power. The resulting fumes, flowing through flue gas ducts to the chimney, give off heat to the water contained in the system of pipes and chambers. In addition to these elements, the device includes loadbearing structure, insulation, housing, accessories, control, and measurement equipment and possibly automation, and for retort boilers: fuel tank, fuel dispenser, burner, fan. For the purpose of analysis of the series of produced steel boilers fired with solid fuels, a division should be made. The division of boilers can be made according to many criteria [7] e.g. according to the material used, according to the efficiency, according to the working medium temperature, according to the refrigerant phase, according to the type of fuel burned, due to the existence or absence of DHW heating, due to the boiler's complexity or the possibility of reconstruction of the furnace in order to adapt to a different type of fuel as

\footnotetext{
* Corresponding author: jaroslaw.bartoszewicz@put.poznan.pl
} 
well as the method of combustion and flue gas discharge [14]. In addition to these basic divisions, could be created additional diversification or evaluation of the selected element or the entire structure. The criterion of these analyzes should always be the assessment of the construction's perfection from different points of view. This article presents an attempt to compare selected construction parameters of five types of boilers currently offered on the Polish market. Comparisons will include energy parameters of the structure, such as the size of the heating surface, fuel consumption, the efficiency of the boiler and other parameters determining the inertia of the system, periodicity of loading, the amount of construction material used and others. The analysis was based on a production program of one hundred thirty producers of low-temperature fossil fuels from western Poland. The latest world research includes e.g. research on the influence of air distribution in the combustion process on the growth of brown coal combustion effects [15], application of exergy analysis in boiler optimization [4] and use of biomass in commercial boilers [9]. Parallel to the research work related to boiler structure analyzes, the researchers analyze burners, fuels [13], their properties and dependencies between them [10].

\section{Analysis of the heating market}

The research method included the analysis of boilers obtained from producers: projects, technological schemes, catalog data, and advertising folders. On this basis, the division into boilers with constant and periodic fuel loading was made. The boilers have been divided into devices that have and do not regulate the air regulation system. In individual groups, interpolation functions of the basic construction parameters in the function of the rated boiler power were determined. These indicators have been used in the power industry for comparison of boilers for years, as they form the basis for the design of new constructions. All results, shown in Figures 1 and 2, relate to offered and sold in Poland, European Union, and worldwide boilers without differentiation for applications in the municipal and industrial sector. Outdated age of boilers used in Poland and types of used boilers [12], provides to rise of dust in the polish air. In almost $70 \%$ of boilers used in Poland are boilers burning coal. Hard coal or lignite is a fuel that contains a large non-flammable part. As a consequence, these compounds, in the form of dust and slag, burden the natural environment. Figure 1a shows the structure of boilers used in Poland for heating residential buildings. As can be seen from the statement, coal boilers firing fuel with nearly $69 \%$ share have a share. Biomass boilers and gas-fired boilers have an equal market share of $14 \%$ each. The remaining market share belongs to other heating systems: solar, electric, heat pumps, gas and oil boilers.

a)

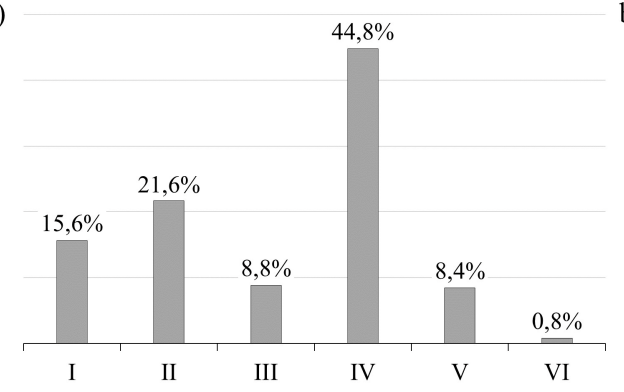

b)

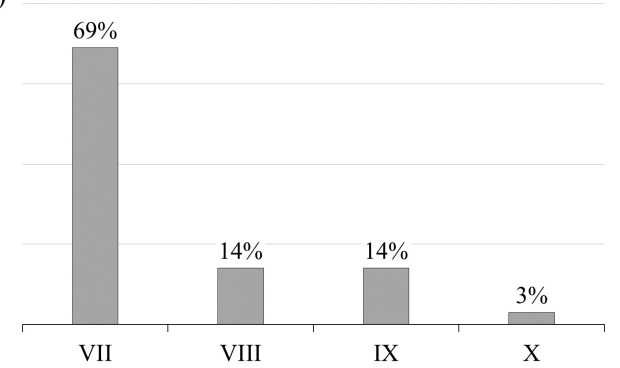

Fig. 1. Structure of boilers operated (a) and the age structure of boilers used in central heating (b): I biomass boilers, II chamber boilers for sorted coal, III chamber boilers with fine coal, IV automatic boilers for sorted coal, V automatic boilers with fine coal, VII coal boilers, VIII biomass boilers, IX gas boilers, $\mathrm{V}$ and $\mathrm{X}$ other boilers. 
The structure of used boilers is not the only reason for the state of the atmosphere in large urban agglomerations. Another factor is the age of heating devices. Because of the prosperity of Polish citizens, the age structure of boilers is very unprofitable. The division of boilers presented in Figure $1 \mathrm{~b}$, due to their age, indicates a less favorable situation. The $16 \%$ of boilers used in Poland are very old boilers, 20 and more years old. These are units that have long exceeded the design lifetime. Similar, negative effects are the use of boilers from ten to twenty years. These sockets often do not have any control automatics that allow them to achieve high efficiency. These are structures less efficient than those currently produced, emitting significant amounts of dust in the atmosphere.

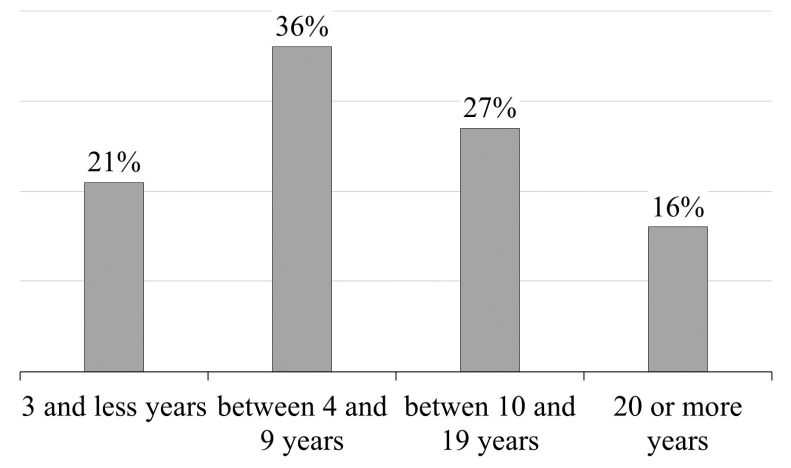

Fig. 2. Specification of boilers authorized for trade [14].

Modern solid fuel boilers, between 4 and 9 years old, are $36 \%$. This is not a satisfactory participation and indicates a significant delay on the market in the modernization of the boiler plant park. Given the fact that modern boilers, up to 3 years, have a market share of $21 \%$. This means that together with boilers for up to 10 years their share is $51 \%$. A positive effect is a $21 \%$ share in the market of the newest boilers. This means that the average for $7 \%$ of boilers is replaced with the latest designs. As a result, boiler restoration may take place over about 14 years. In the case of new boiler designs, check tests should be carried out in certified laboratories. Figure 2 shows the average annual share of boilers with and without automatic fuel feeders and combustion of sorted and fine coal. The number of boilers burning sorted fuel is $67 \%$. This means that boilers designed for burning coal of a certain size have the largest market share. Such devices have higher efficiency. This effect is obtained by better design of the combustion chamber and a better ability to control the process of descaling. Boilers designed to burn any fuel have a small share, about $17 \%$. These are universal boilers that can burn coal of various sizes, but the effect is lower efficiency. The market share of biomass boilers is not satisfactory. This share does not exceed $15 \%$. All the reasons discussed, presented in the diagrams indicate the sources of high pollution and the directions in which the individual energy sector should develop. The boiler designs offered in the European Union are similar in terms of construction and work efficiency. This effect was achieved by unifying the relevant standards in Europe, and specifically the emission requirements. However, there are areas that are not ordinated in the construction of boilers. We include fans that supply air to the combustion process. There are currently no requirements in the European Union relating to the efficiency of low power fans [3]. Generalizing the construction of solid fuel boilers in Europe are similar, but they can differ in construction details. 


\section{Constructions of central heating coal boilers}

Low-temperature coal-fired boilers can be divided into several types. These are boilers burning coal and producing water at a temperature up to $95^{\circ} \mathrm{C}$ and 3 bar of overpressure. The split depends on the method of fuel delivery to the combustion chamber. Author distinguish boilers with periodic loading and continuous loading, for which the fuel feeder is responsible. oilers with periodic fuel loading are in operation on boilers that are not equipped with an air dosing system (Universal Steel Boiler - USB) and equipped with oxidizer control and dosing systems for the combustion chamber. The second group is also divided into subgroups: boilers in which the exhaust gas moves in a vertical direction and then float out (USB-V) and the boilers, in which the springs flow horizontally in the back of the boiler, to the flue (USB-H). In the case of boilers with fuel feeders, authors distinguish: boilers fitted with screws that rotate coal to the burner (SB-S) and boilers equipped with piston feeders which periodically sow into the combustion chamber through the cam mechanism (SB-P). Figure 3 shows the division of boilers due to the existence of an air dosing system and a fuel supply system to the combustion chamber. Figure 4 presents selected designs of low-temperature coal-burning boilers. This division is the result of work carried out in recent years and presented in few papers e.g. analysis of the possibilities of application of numerical methods in the improvement of the operating efficiency of lowpower boilers analysis [1] and control systems [11] or testing of automatic biomass boilers and analysis flows inside boilers [2].

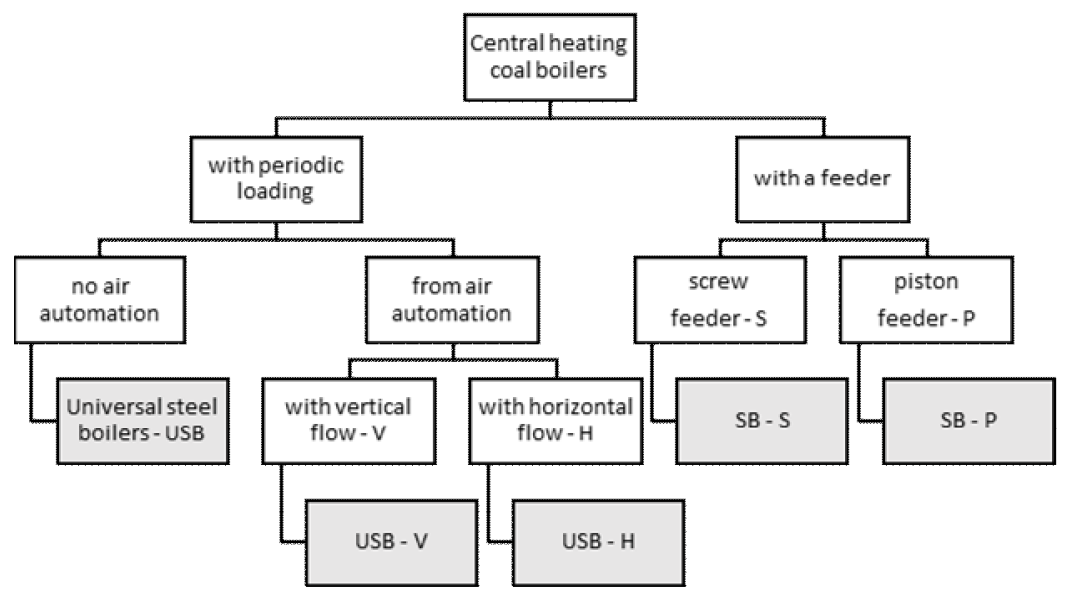

Fig. 3. The Division of coal-fired boilers $[8,14]$

The currently produced domestic coal boilers, small and medium thermal power, can be divided using the general method of classification according to the fuel combustion technique: coal combustion [8] and division of boilers [14]:

- boilers with periodic manual or mechanical loading of fuel, in which the technique of lower combustion in the whole bed volume is used, so-called countercurrent combustion with natural air flow, most often in boilers for coarse-coal fuel,

- boilers with periodic manual or mechanical fuel loading, in which the technique of lower combustion is used in part of the bed volume, so-called co-current combustion with natural or forced air flow in boilers for coarse-grained and medium-fine fuel and in boilers for fine-cut and fine fuel,

- boilers with continuous automatic fuel supply control, with adjustable fuel portions and the amount of air, supplied to the combustion chamber for fine-cut and fine fuel, in 
which there are furnaces called retorts with a screw feeder or lower hearth furnaces with a piston feeder and grate.

USB boilers (universal steel boilers) are the simplest and cheapest devices. These boilers are designed for burning low-grade fuel, unsorted coal or mixed fuel. They do not have advanced equipment like a controller or even a fan. The regulation of the heating water temperature is made by a simple mechanical device called a draft regulator. Its operation consists in increasing or decreasing the gap in the door of the ash pan, which changes the amount of air supplied to the combustion chamber. USB boilers in comparison to more advanced constructions are characterized by quite a low efficiency. The USB-V and USB-H boilers are improved versions of traditional, universal steel boilers. The only difference between the USB-V and USB-H boilers is the shape of the heat exchangers. Modern boilers are usually fired with coal, but some models also allow combustion of other coal sizes. These boilers are equipped with a microprocessor controller that controls the blower fan. As a result, the temperature regulation is easier and more accurate, the boiler adjusts its thermal power to variable demand, consumes less fuel. Although it is slightly more expensive than a traditional USB boiler, thanks to these advantages it is cheaper to operate. Boilers with a feeder are the most advanced devices available on the market. The operation of boilers with feeders is controlled by a microprocessor controller. The automation system selects the operating parameters and regulates the boiler's power depending on the fuel burned or the required temperature. Due to the fact that all aspects of the combustion process are regulated, the boiler is characterized by high efficiency and relatively low emission of harmful substances. With the models available on the market, the boilers with feeders are the most expensive, but their advantage is the fact that the fuel in the tank should be supplemented only every few days. The coal is most often the coal of pea assortment (hence the so-called eco-pea coal is often used). Many models of boilers with feeders are equipped with an additional grate, which allows the boiler to work in the absence of power - this boiler then works like a traditional hopper.

a)

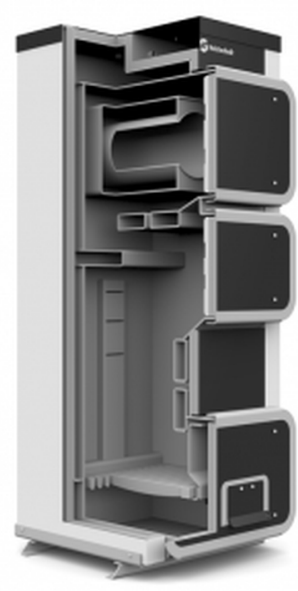

b)

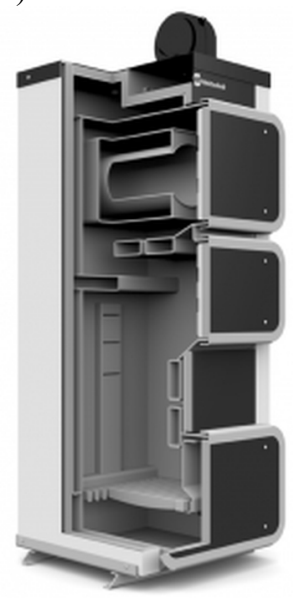

c)

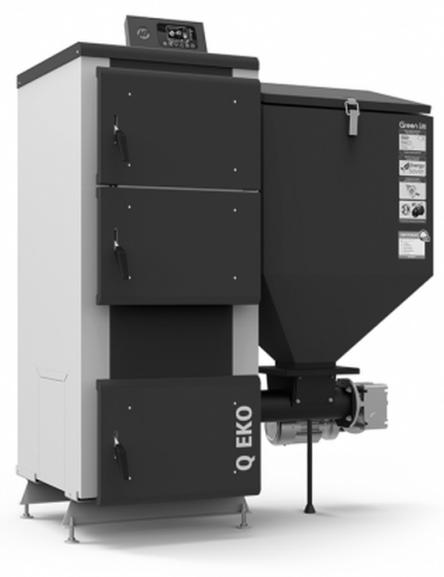

Fig. 4. Examples of boiler designs: universal steel boiler (a), universal steel boiler with the vertical flow (b), steel boiler with a screw feeder (c) [5].

\section{Analysis results}

The results of the analysis presented in the article concern research carried out in certified laboratories. New designs offered on the domestic and European market require 
legalization tests in which the basic parameters of boiler operation are checked. The most important are efficiency, losses to the environment, fuel consumption, and others as a function of boiler power. The power is set for the same set temperature difference between the outlet flowing out of the boiler and returning to the boiler. The difference is $20 \mathrm{~K}$ and the range is $60 \div 80^{\circ} \mathrm{C}$ or $60 \div 75^{\circ} \mathrm{C}$. This applies to low-temperature water boilers with municipal applications and to a certain range of industries. We do not include condensing boilers for this type of operation with underfloor heating.

All comparative analysis results are summarized in Table 1. The table summarizes the results of the averaged values with each other: efficiency, diameter of water connections, one-time charging of fuel, the weight of the boiler, water capacity, surface heated in the boiler, loads on the heating surface for five types of boilers (USB, USB-V, USB-H, SB-S, SB-P). Based on the analysis of several dozen production programs of companies from Poland, average values or simple algebraic functions were obtained allowing them to be compared with each other. Figures 5 and 6 present examples of statements for 2006 and 2017 showing the changes in efficiency in universal steel boilers and the weight of construction material used for the boiler for universal steel boilers with horizontal flue gas flow. The symbol Q $(\mathrm{kW})$ in the table indicates the nominal boiler power.

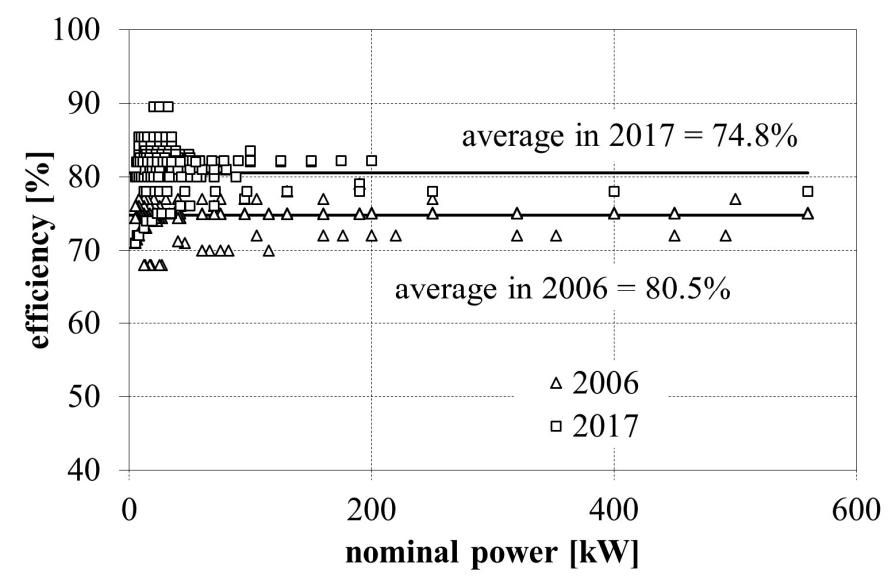

Fig. 5. Comparison of the efficiency of USB in the year 2006 and 2017.

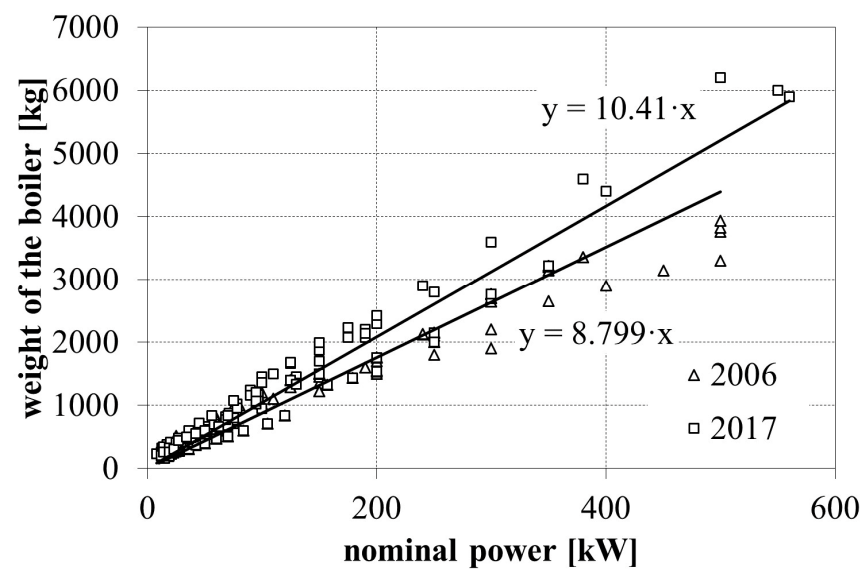

Fig. 6. Comparison of the mass of boilers used the material for boilers with horizontal flow. 
The results of the analysis are presented in Table 1 in the form: average values for the whole range of boiler power of a given series of types and linear functions. For example:

- the average efficiency of all used universal USB boilers has increased in the last decade from $78.4 \%$ to $80.5 \%$ (this is a very good result), but for USB-H boilers there was a $0.8 \%$ drop in efficiency,

- the weight of the fuel once loaded into the boiler determines the operating time of the unattended boiler, for boilers with feeders this indicator is not analyzed, it is replaced by the capacity of the boiler tank,

- the weight of the boiler (the weight of steel used for the construction) determines approximately the cost of the material, described by linear functions (the increase in the multiplier means the greater mass of the construction material),

- water capacity determines the inertia of a working water boiler (when choosing a boiler, follow the rule, the smaller the building surface, the smaller the water capacity of the boiler),

- increasing the load on the heating surface of the boiler means better use of it, with the simultaneous threat of lower boiler life.

Table 1. Comparison of the results of the comparative analysis

\begin{tabular}{|c|c|c|c|c|c|c|}
\hline & Year & USB & USB-H & USB-V & SB-S & SB-P \\
\hline Efficiency [\%] & $\begin{array}{l}2006 \\
2017\end{array}$ & $\begin{array}{l}74.80 \\
80.50\end{array}$ & $\begin{array}{l}82.30 \\
82.02\end{array}$ & $\begin{array}{l}83.11 \\
82.20\end{array}$ & $\begin{array}{l}81.67 \\
84.99\end{array}$ & $\begin{array}{l}82.13 \\
86.34\end{array}$ \\
\hline $\begin{array}{l}\text { The diameter of } \\
\text { water connections } \\
{[\mathrm{mm}]}\end{array}$ & $\begin{array}{l}2006 \\
2017\end{array}$ & $\begin{array}{l}48 \div 168 \\
25 \div 76.2\end{array}$ & $\begin{array}{l}50 \div 150 \\
32 \div 76.2\end{array}$ & $\begin{array}{l}50 \div 108 \\
32 \div 76.2\end{array}$ & $\begin{array}{l}50 \div 150 \\
32 \div 76.2\end{array}$ & $\begin{array}{l}50 \div 114.3 \\
25.4 \div 76.2\end{array}$ \\
\hline $\begin{array}{l}\text { One-time charging } \\
\text { of fuel }[\mathrm{kg}]\end{array}$ & $\begin{array}{l}2006 \\
2017\end{array}$ & $\begin{array}{l}=0.943 \cdot \mathrm{Q} \\
=2.205 \cdot \mathrm{Q}\end{array}$ & $\begin{array}{l}=2.143 \cdot \mathrm{Q} \\
=2.183 \cdot \mathrm{Q}\end{array}$ & $\begin{array}{l}=1.850 \cdot \mathrm{Q} \\
=2.007 \cdot \mathrm{Q}\end{array}$ & - & - \\
\hline $\begin{array}{l}\text { The weight } \\
\text { of the boiler }[\mathrm{kg}]\end{array}$ & $\begin{array}{l}2006 \\
2017\end{array}$ & $\begin{array}{l}=12.09 \cdot \mathrm{Q} \\
=12.10 \cdot \mathrm{Q}\end{array}$ & $\begin{array}{l}=9.374 \cdot \mathrm{Q} \\
=8.966 \cdot \mathrm{Q}\end{array}$ & $\begin{array}{l}=8.799 \cdot \mathrm{Q} \\
=10.41 \cdot \mathrm{Q}\end{array}$ & $\begin{array}{l}=11.04 \cdot \mathrm{Q} \\
=11.93 \cdot \mathrm{Q}\end{array}$ & $\begin{array}{l}=10.91 \cdot \mathrm{Q} \\
=10.89 \cdot \mathrm{Q}\end{array}$ \\
\hline $\begin{array}{l}\text { Water capacity } \\
{\left[\mathrm{dm}^{3}\right]}\end{array}$ & $\begin{array}{l}2006 \\
2017\end{array}$ & $\begin{array}{l}=6.100 \cdot \mathrm{Q} \\
=5.354 \cdot \mathrm{Q}\end{array}$ & $\begin{array}{l}=2.992 \cdot \mathrm{Q} \\
=3.934 \cdot \mathrm{Q}\end{array}$ & $\begin{array}{l}=2.936 \cdot \mathrm{Q} \\
=3.363 \cdot \mathrm{Q}\end{array}$ & $\begin{array}{l}=2.811 \cdot \mathrm{Q} \\
=3.713 \cdot \mathrm{Q}\end{array}$ & $\begin{array}{l}=4.173 \cdot \mathrm{Q} \\
=3.653 \cdot \mathrm{Q}\end{array}$ \\
\hline $\begin{array}{l}\text { Surface heated } \\
\text { in the boiler }\left[\mathrm{m}^{2}\right]\end{array}$ & $\begin{array}{l}2006 \\
2017\end{array}$ & $\begin{array}{l}=0.142 \cdot \mathrm{Q} \\
=0.132 \cdot \mathrm{Q}\end{array}$ & $\begin{array}{l}=0.092 \cdot \mathrm{Q} \\
=0.097 \cdot \mathrm{Q}\end{array}$ & $\begin{array}{l}=0.084 \cdot \mathrm{Q} \\
=0.097 \cdot \mathrm{Q}\end{array}$ & $\begin{array}{l}=0.111 \cdot \mathrm{Q} \\
=0.098 \cdot \mathrm{Q}\end{array}$ & $\begin{array}{l}=0.090 \cdot \mathrm{Q} \\
=0.091 \cdot \mathrm{Q}\end{array}$ \\
\hline $\begin{array}{l}\text { Loads on the } \\
\text { heating surface } \\
{\left[\mathrm{kW} / \mathrm{m}^{2}\right]}\end{array}$ & $\begin{array}{l}2006 \\
2017\end{array}$ & $\begin{array}{l}7.16 \\
8.64\end{array}$ & $\begin{array}{l}9.63 \\
9.51\end{array}$ & $\begin{array}{l}10.3 \\
9.62\end{array}$ & $\begin{array}{l}9.32 \\
9.88\end{array}$ & $\begin{array}{l}9.97 \\
9.71\end{array}$ \\
\hline
\end{tabular}

\section{Conclusions}

The article presents the interpolation equations obtained after analyzing the structure of boilers manufactured up to 2006 and now in Poland. Interpolation formulas or average results provide the basis for assessing the direction of changes in the boiler construction. The results presented in the table and shown in the example drawings are the basis for designing new constructions or verifying how the newly designed boilers are presented against the background of other manufacturers' designs. The use of indicators analyzed in the article is common in the high power industry. The article presents the first attempt to use them to analyze the very large production of low-power boilers for single-family houses. The results presented in Table 1 allow to determine the development trends in the construction of small-capacity water boilers. There was an increase in efficiency in three 
cases and a decrease in fitness in two cases. The efficiency change is related to the change in the heat load of the heated surface. Reducing this indicator results in reduced efficiency but longer boiler life. The capacity of the combustion chambers increased significantly, i.e. the burning time of the fuel portion. The weight of the boilers remains at a similar level. The costs of construction material do not change significantly. The water capacity of the boiler in three cases decreased, and in two it increased, which affects the inertia of boilers.

\section{References}

1. J. Bartoszewicz, CHISA 2012, Symp. Enviro. Engin., P3.151 (2012)

2. J. Bartoszewicz, L. Bogusławski, Archives of Thermodynamics, 37, 107-120 (2016)

3. J. Bartoszewicz, A. Nygard, R. Urbaniak, J. of Power Technology, 97, 69-74 (2017)

4. A. Behbahaninia, S. Ramezani, M.L. Hejrandoost, Energy, 140, 253-260 (2017)

5. Heiztechnik Man. Com. Lim., <heiztechnik.pl/ 2018>, accessed 15.04.2018

6. H. Koczyk, Heating for practitioners (Systherm Serwis Pub.House 2002) (in polish)

7. S. Kruczek, Boilers (Wroclaw Uni.Tech.Pub.House 2001) (in polish)

8. K. Kubica, Scientific and Technical Conference Energy, 2 31-42 (2000)

9. I. Mediavillaa, E. Borjabada, M.J. Fernándeza, R. Ramosa, P. Péreza, R. Badosa, J.E. Carrascob, Biofuels 141, 1845-1856 (2017)

10. K.W. Stahmer, M. Gerhold, Chem. Eng. Trans., 48, 295-300 (2016)

11. R. Urbaniak, J. Bartoszewicz, W. Judt, Heat Transfer Reaserch, 49, 675-683 (2012)

12. R. Urbaniak, J. Bartoszewicz, R. Kłosowiak, Polish J of Environmental Studies, 24, 2223-2230 (2015)

13. N.A. Yunus, N.N. Norfatiha, N.M. Zaharia, Chem. Eng. Trans., 56, 1063-1068 (2017)

14. Zawistowski J., Magazine of Installer, 1, 89 (2006)

15. L. Zixiang, M. Zhengqing, Z. Yan, W. Shurong, L. Jiangtao, Energy, 152, 804-817 (2018) 